\title{
Referenciação e sincretismo: o caso dos vídeos que divulgam ciência no Youtube
}

\author{
Referencing and syncretism: the case of webvideos that disseminate science on YouTube
}

\section{Marcos Filipe Zandonai \\ Maria Eduarda Giering}

\author{
Universidade do Vale do Rio dos Sinos - UNISINOS - São Leopoldo - Brasil
}

\begin{abstract}
Resumo: O presente artigo aborda o fenômeno da referenciação em um vídeo de divulgação científica do YouTube. O objetivo principal do estudo é compreender quais são as funções desempenhadas pelos elementos visuais (desenhos digitais e performance teatral) na produção dos significados sobre os objetos de discurso. Para tanto, foram estabelecidos os seguintes objetivos específicos: i) identificar os casos de correferencialidade entre nomeações lexicalizadas e mensagens visuais, descrevendo as operações semânticas engendradas por essa união e ii) analisar qualitativamente esses elos coesivos considerando os componentes da situação comunicativa (de midiatização da ciência). O funcionamento das construções referenciais é averiguado à luz da Linguística Textual (CAVALCANTE, 2003) e dos estudos sobre a midiatização da ciência (CHARAUDEAU, 2008), visto que este é o entorno da atividade linguageira, permeado por rituais e coerções que sobredeterminam as formas lexicais e semiológicas para explicar ciência. Concebe-se o vídeo como um objeto sincrético, o que requer que sejam utilizadas noções da Semiótica (BARROS, 1990; GREIMAS e COURTÉS, 2013; PIETROFORTE, 2008), e da comunicação não verbal (RECTOR E TRINTA, 2005) para mapear o semissimbolismo do texto e, por conseguinte, obter as unidades de significação do episódio. Empreende-se uma análise qualitativa do corpus. Os resultados evidenciaram os fatores semântico-discursivos e cognitivos que fazem funcionar a "referenciação sincrética", alargando-se a noção de anáfora. Na sequencialidade e na progressão textual, são verificados jogos de representação que estão intimamente vinculados aos conhecimentos que emergem da situação de midiatização da ciência.
\end{abstract}

Palavras-chave: Referenciação. Divulgação Científica Midiática. Semiótica. YouTube.

Abstract: This paper deals the phenomenon of referencing in a scientific popularization video of YouTube. The main aim is comprehending which are the functions undertaken by the visual elements (icons and theatrical performance) to the production of meanings about the discourse objects. For that, there were established the following specific aims: to identify cases of co-referentiality between lexicalized designations and visual messages, describing the semantic operations engineered by this union and ii) to analyze qualitatively these cohesive links considering the components of communicative situation (of science midiatization). The operation of the referential constructions is investigated in the lights of Textual Linguistics (CAVALCANTE, 2003) and of the studies on science midiatization (CHARAUDEAU, 2008), once this is the surrounding of language activity permeated by rituals and constraints that overdetermine the lexical and semiotic choices to explain science. The webvideo examined it is conceived as a syncretic text, which requires that be used concepts from Semiotics (BARROS, 1990; GREIMAS e COURTÉS, 2013; PIETROFORTE, 2008) and from nonverbal communication (RECTOR E TRINTA, 2005), to map the semi-symbolism of text and, therefore, to obtain signification macrounities of the episode. The results showed semantic-discursive and cognitive factors that make the "syncretic referencing" work, extending the notion of anaphora. In sequential and textual progression, there are verified ways of representation which are closely linked to knowledge that emerges from situation of science midiatization.

Keywords: Referencing. Scientific Popularization in the Media. Semiotics. YouTube. 


\section{Introdução}

Dos benefícios propiciados pela divulgação científica, tais como a inclusão social, a solução de problemas na saúde (em campanhas, por exemplo), a inovação na educação científica, entre outras, resulta o valor de se analisar os discursos dessa esfera de atuação humana. Como acontece a divulgação científica (doravante $\left.\mathrm{DC}^{1}\right)$ ? Que representações de ciência circulam socialmente? Quais seus impactos?

Os canais de ciência no ciberespaço (podcasts, vídeos do YouTube, blogs) têm adquirido um papel formativo significativo na difusão do saber científico. Cumpre entender de que modo são organizados os textos de DC dessas mídias, como eles produzem sentidos uma vez tendo de se dirigir a pessoas não suficientemente familiarizadas com a linguagem especializada.

O nosso interesse pelas produções audiovisuais, pelas encenações do YouTube - como mostra recente matéria da revista Exame (2015) online sobre vídeos de DC do YouTube -, levou-nos a empreender este estudo, cujo objetivo principal foi verificar o papel da imagem na construção dos sentidos sobre os tópicos de ciência propostos pelos divulgadores. Para tanto, estabelecemos os seguintes objetivos específicos: i) identificar os casos de correferencialidade entre nomeações lexicalizadas e mensagens visuais, descrevendo suas operações semânticas e ii) analisar qualitativamente esses elos referenciais/coesivos considerando os componentes da situação comunicativa (de midiatização da ciência).

A hipótese que guiou nosso estudo é a de que a referenciação é construída também pelo aparato visual dos vídeos, e não apenas por meio das expressões linguisticamente materializadas. Intentamos, então, compreender como agem esses elementos visuais - no caso de nosso corpus, a performance teatral e as imagens digitais - ao

\footnotetext{
1 No presente artigo, serão utilizadas as siglas DC (para divulgação científica) e DCM (para divulgação científica midiática).
}

combinarem-se com o discurso falado orientado para a DC.

Este artigo $^{2}$ está organizado da seguinte maneira: após esta introdução, exporemos alguns fundamentos sobre midiatização da ciência e referenciação. $\mathrm{Na}$ terceira seção, situamos os conceitos da Semiótica pertinentes para o tratamento do objeto sincrético com o qual lidamos. Por conseguinte, são elucidados os aspectos metodológicos da pesquisa, para, em seguida, serem expostos os resultados da análise das marcas de referenciação.

\section{A divulgação científica midiática e os processos de referenciação nos audiovisuais}

As diferentes modalidades de linguagem que concorrem nas composições da hipermídia fazem parte do universo da comunicação na Internet, que, a nosso ver, merece investigação científica, mas acompanhada de um repensar sobre as categorias de análise e, inclusive, sobre as práticas de assimilação dos conteúdos de ciência e tecnologia (doravante C\&T), devido às combinações verbo-visuais propiciadas pelas tecnologias de informação.

As escolhas lexicais e visuais, independentemente do suporte ou gênero, usadas para garantir a unidade informacional ou atualizar os tópicos, para abordar C\&T, são influenciadas pelos componentes da situação de midiatização da ciência (CHARAUDEAU, 2008). Se os vídeos são direcionados a um público não especialista, é evidente que a equipe de produção precisa calcular quais são os recursos adequados para ser compreendida, pois, na DC, "a identidade dos parceiros em relação à posição de saber é acentuadamente assimétrica", contrariamente ao que acontece no contexto acadêmico", como enfatiza Giering (2010, p. 130). Os divulgadores de ciência fazem apostas ao constituir a fala, com base nas circunstâncias do intercâmbio linguageiro;

\footnotetext{
${ }^{2}$ Os dados aqui apresentados resultam de uma pesquisa de Dissertacão de Mestrado recentemente defendida, que contemplou dois vídeos do YouTube de divulgação científica. Contemplamos, no presente artigo, entretanto, os dados considerados mais significativos, referentes a apenas um vídeo.
} 
reconhecem "o conjunto das condições nas quais se realiza qualquer ato de comunicação" (CHARAUDEAU e MAINGUENEAU, 2004, p. 132) que é nada mais nada menos que o contrato de comunicação. Esse contrato fornece ao locutor as coordenadas (o lugar onde está, os objetivos comunicativos, a identidade de seu interlocutor, etc.) (CHARAUDEAU, 2006) para poder comunicar.

Charaudeau (2008) postula as quatro restrições do contrato de comunicação de midiatização da ciência, as quais implicam a corporificação de certas formas textuais em detrimento de outras (CHARAUDEAU, 2006). De acordo com o linguista (2008), a restrição de visibilidade faz com que a mídia selecione fatos insólitos, passíveis de gerar algum impacto ou polêmica. Temos, também, a restrição de legibilidade, que pressiona o locutor a adotar retórica simples e iconografia abundante (com boxes, resumos, infográficos, etc.). Já a restrição de seriedade, por seu turno, decorre do compromisso do veículo de comunicação em manter-se (ou mostrar-se) credível e confiável, com o uso de argumentos de autoridade, por exemplo. Por fim, lembramos que a restrição de emocionalidade é aquela marcada por escolhas textuais que sensibilizam os leitores e dramatizam os fatos noticiados.

É importante considerar que, para Charaudeau (2006), a finalidade do discurso de $\mathrm{DCM}^{3}$ é dupla: ao mesmo tempo em que busca informar (fazer saber), o órgão de produção da informação precisa suscitar o interesse das pessoas, ou seja, captar (fazer sentir) (CHARAUDEAU, 2006).

Neste artigo, procuramos compreender de que maneira as imagens (ou desenhos digitais) e os movimentos corporais do divulgador participam da referenciação. Para tanto, utilizamos o quadro geral de processos referenciais de Cavalcante (2003), bem como outras de suas contribuições teóricas (CAVALCANTE 2011), que está sintetizado no Quadro 1, na sequência.

\footnotetext{
3 Sigla utilizada no presente trabalho para designar a Divulgação Científica Midiática, que é uma ramificação da Divulgação Científica.
}

Quadro 1 - Processos referenciais ${ }^{4}$

\begin{tabular}{|c|c|}
\hline $\begin{array}{l}\text { Processo } \\
\text { referencial (mais } \\
\text { genericamente) }\end{array}$ & $\begin{array}{l}\text { Tipo de retomada (mais } \\
\text { especificamente) }\end{array}$ \\
\hline $\begin{array}{l}\text { Introdução } \\
\text { referencial sem } \\
\text { continuidade }\end{array}$ & $\begin{array}{l}\text { É o caso de dêiticos } \\
\text { espaciais ("aqui", "lá") e } \\
\text { textuais ("aqui", "acima", } \\
\text { "abaixo"), por exemplo, que } \\
\text { não prescindem de } \\
\text { continuidade. }\end{array}$ \\
\hline \multirow[t]{2}{*}{$\begin{array}{l}\text { Continuidades } \\
\text { referenciais }\end{array}$} & $\begin{array}{l}\text { Anáforas correferenciais } \\
\text { cossignificativas (sinônimos) }\end{array}$ \\
\hline & $\begin{array}{l}\text { Anáforas correferenciais } \\
\text { recategorizadoras } \\
\text { (recuperam o referente com } \\
\text { outras palavras - por } \\
\text { hiponímia, pronome, } \\
\text { expressão definida, etc.). }\end{array}$ \\
\hline $\begin{array}{l}\text { Anáforas parciais } \\
\text { cossignificativas }\end{array}$ & $\begin{array}{l}\text { Retomadas por: sintagma } \\
\text { nominal, } \\
\text { indefinidos ou numomes } \\
\text { adjetivos. Recuperam só } \\
\text { uma parte do referente. }\end{array}$ \\
\hline $\begin{array}{l}\text { Anáforas } \\
\text { indiretas }\end{array}$ & $\begin{array}{l}\text { Anáforas encapsuladoras e } \\
\text { rótulos, por exemplo. Em } \\
\text { especial, os rótulos exigem } \\
\text { que se recorra a } \\
\text { conhecimentos contextuais. } \\
\text { Nesse grupo de anáforas, } \\
\text { estão inseridas as que } \\
\text { requerem algum tipo de } \\
\text { inferência, como as } \\
\text { associativas. }\end{array}$ \\
\hline
\end{tabular}

Fonte: elaborado pelos autores, com base em

Cavalcante (2003; 2011).

Concebemos o texto como portador de várias semioses, e não apenas como materialidade linguística, entendendo-o como "manifestação material (verbal e semiológica: oral/gráfica, gestual, icônica, etc.) da encenação de um ato de comunicação, numa situação dada, para servir ao Projeto de fala de um determinado locutor" (CHARAUDEAU, 2009, p. 77).

O comportamento da referenciação em texto com mais de uma modalidade de linguagem já foi investigado por alguns autores (CUSTÓDIO FILHO, 2011; GIERING, 2012). Giering (2012), por exemplo, expande a concepção da correferencialidade, apontando o papel das inscrições visuais na construção de objetos de discurso em hiperestruturas

\footnotetext{
${ }^{4}$ A classificação é extensa. Por isso, não será apresentada em sua integralidade aqui. O Quadro contempla aqueles processos considerados mais relevantes para a pesquisa.
} 
textuais, aquelas reportagens de DC que apresentam várias entradas de leitura (boxes, tabelas, gráficos) além do chamado "texto principal".

Sabemos que nomear e recategorizar os objetos discursivos depende grandemente da emergência de fatores off-line, cognitivos e pragmático-culturais, evidenciados, por exemplo, nas metáforas. Por isso, assumimos uma visão sociocognitivo-discursiva da referenciação (CAVALCANTE, 2011).

Expomos, na próxima seção, algumas ferramentas que nos ajudaram a tratar dos componentes não verbais.

\section{A imagem produzindo sentidos: semiótica e comunicação não verbal ${ }^{5}$}

O texto é uma realização gráfica ou fônica que se dá no eixo sintagmático, incluindo, aí, as cadeias sintagmáticas de "semióticas não linguísticas: um ritual, um balé podem ser considerados textos ou discursos", conforme a semiótica greimasiana (GREIMAS E COURTÉS, 2013, p. 503). Nosso corpus é um texto sincrético (GREIMAS E COURTÉS, 2013; PIETROFORTE, 2008), pois, nele, vários meios de expressão agem simultaneamente.

Há, no plano de expressão, também imagens, como fotos e outras criações estéticas. Neste trabalho, optamos por nomear esses itens imagéticos por "imagens digitais", haja vista que o adjetivo digital é coerente com o entendimento de Dubois (2004) a respeito dos regimes de visualidade da informática.

Adotamos a classificação de gestuemas de Rector e Trinta (2005) para mensurar a funcionalidade dos movimentos corporais da jornalista no episódio, que também fazem parte do plano de expressão do vídeo. Tal classificação prevê casos como: gestuema adaptador, ligado a traços da pessoa, como cacoetes; gestuema pictográfico, que, por sua vez, se subdivide em dêitico (utilizado para

\footnotetext{
5 A partir deste capítulo, em alguns momentos, utilizaremos barras como estas: /ser/, /fazer/, /parecer/, etc., conforme codificação amplamente empregada em Semiótica (BARROS, 2001). Os lexemas recebem barras justamente para que sejam diferenciados do restante do enunciado, pois eles são categorias modais da imanência; têm valor metalinguístico.
}

indicar determinado objeto num espaço) ou gestobatuta (movimento que enfatiza determinada palavra ou frase, como que regendo a fala) (RECTOR E TRINTA, 2005), entre vários outros, os quais não cabe explicitar no presente artigo.

Pietroforte (2008) nos instrui a examinar a especificidade da imagem, em seus planos de composição, conforme Quadro 2, alertando que as formas figurativas ou lexicais da superfície textual são "motivadas" por conteúdos da imanência.

Quadro 2 - Relação semissimbólica

\begin{tabular}{|c|c|c|}
\hline \multirow[t]{3}{*}{$\begin{array}{l}\text { Plano de } \\
\text { expressão }\end{array}$} & categoria eidética & $\begin{array}{l}\dot{E} \text { relativa à } \\
\text { manifestação } \\
\text { por meio da } \\
\text { forma (reto x } \\
\text { curvo, angular x } \\
\text { arredondado, } \\
\text { etc.). }\end{array}$ \\
\hline & categoria cromática & $\begin{array}{l}\text { Concerne à } \\
\text { manifestação } \\
\text { por meio da } \\
\text { cor, } \\
\text { abrangendo as } \\
\text { oposições de } \\
\text { valor (claro x } \\
\text { escuro) } \\
\text { tonalidade } \\
\text { (quente x frio), } \\
\text { por exemplo. }\end{array}$ \\
\hline & $\begin{array}{l}\text { categoria } \\
\text { topológica }\end{array}$ & $\begin{array}{l}\text { Relativa } \\
\text { distribuição dos } \\
\text { elementos no } \\
\text { espaço. } \\
\text { Trabalha } \\
\text { dimensões } \\
\text { (grande } \\
\text { pequeno) } \\
\text { posições (alto } \\
\text { baixo), etc. }\end{array}$ \\
\hline $\begin{array}{l}\text { Plano de } \\
\text { conteúdo }\end{array}$ & $\begin{array}{l}\text { acontecimentos, } \\
\text { aspectos ou semas } \\
\text { da imanência }\end{array}$ & $\begin{array}{l}\text { Um pouco das } \\
\text { categorias } \\
\text { usadas poderá } \\
\text { ser examinada } \\
\text { adiante, no } \\
\text { Quadro } 3 .\end{array}$ \\
\hline
\end{tabular}

Fonte: adaptado de Pietroforte (2008, p. 30).

Verificar a significação e os efeitos de sentido advindos da referenciação do vídeo, com várias semioses, requer que examinemos 0 semissimbolismo (a relação existente entre as categorias de conteúdo e as categorias da expressão) (PIETROFORTE, 2008). As categorias de conteúdo 
"independem, em parte, do plano de expressão escolhido para manifestá-las" (PIETROFORTE, 2008, p. 37). As categorias de expressão apenas formalizam algo que é da seara das ideias, do plano de conteúdo (vide Quadro 2).

Metodologicamente, decidimos acessar, na análise do corpus, aqueles conteúdos pertencentes ao nível narrativo do vídeo, que é o nível intermediário do percurso gerativo do sentido ${ }^{6}$. As situações narrativas baseiam-se em pressuposições lógicas: o sujeito, para empreender um fazer, precisa ser dotado de atributos para tal fazer, por exemplo. $\mathrm{Na}$ gramática narrativa, é o destinador-manipulador, um ser virtual, pressuposto logicamente, que dota algum outro sujeito de atributos modais para fazer algo - este fazer pode ser informar ciência, por exemplo. Os conceitos narrativos - garantidores dos signos do plano de expressão do vídeo - que utilizamos para atender aos objetivos deste trabalho serão mais bem explicados no Quadro 3 (página 9).

Ainda quanto à gramática narrativa, temos a duratividade, um sema aspectual, uma unidade que faz o processo durar, abrangendo o impulso, o começo e o final do processo narrativo. A duratividade é a "harmonia", a cadência de acontecimentos prevista (por exemplo, socializar o conhecimento científico). Mas esse processo "natural" pode receber interferências, a que chamaremos de tensão ou contração, neste texto. Essa dicotomia duratividade/contração provém da ideia de que os percursos de significação são permeados por variações tensivas (BARROS, 2001), que entram no percurso trazendo valores que contrastam com os da duratividade (por exemplo, os valores do senso comum contrastando com os valores da ciência).

\section{Aspectos metodológicos}

\footnotetext{
${ }^{6}$ Trata-se do modelo de análise, elaborado por Greimas, que permite explicar a produção do significado do texto como uma formação em patamares, que vai do lógico-abstrato ao mais concreto e discursivo, mas centra-se prioritariamente nas estruturas interiorizadas do texto (FIORIN, 2014). O nível fundamental trata das oposições semânticas mínimas de um texto, sendo o mais abstrato de todos (FIORIN, 2014). O nível mais concreto é o discursivo, que inventa os atores, símbolos e papéis enunciativos veiculadores dos conteúdos fundamentais (BARROS, 2001). O nível narrativo, por seu turno, é composto por entidades em transformação, pressupondo-se o texto como uma história, em que actantes fazem buscas (BARROS, 2001), as quais se dão por meio de intervenções no /ser/ e no /fazer/.
}

No presente trabalho, examinamos a referenciação, com suas múltiplas semioses, em um vídeo do canal Além da Bio. Optamos por este canal devido às seguintes razões:

1) interesse por expandir os estudos já realizados acerca das características dos discursos de DCM, acrescentando a problemática dos textos cujo sistema semiótico é diferente daqueles que privilegiam o material verbal.

2) interesse pelas novas mídias de DC e pelo funcionamento da modalidade visual (especialmente da performance corporal e teatral dos divulgadores) na constituição dos textos dessas mídias; portanto, escolheu-se vídeos em que os divulgadores faziam encenações, utilizando a linguagem corporal;

3) o fato de o canal Além da Bio estar vinculado ao Science Blogs Brasil, o que o indexa ao campo da C\&T, assegurando-se, assim, que as temáticas do corpus são desenvolvidas sob a ótica da ciência. $\mathrm{O}$ Science Blogs Brasil é uma rede de blogs de Ciências cujo objetivo é propiciar espaços de socialização de conteúdos de cunho científico por diversos blogueiros especialistas (SCIENCEBLOGS, 2013).

A transcrição dos dados de áudio do episódio se deu conforme as convenções de Jefferson (2004).

Cabem alguns comentários gerais sobre 0 canal Além da Bio: O canal foi inscrito no YouTube no ano de 2013 e, na sua página, é apresentado da seguinte maneira: "Divirta-se aprendendo biologia e um pouco mais! " (ALÉM DA BIO, 2013a), o que já evidencia o foco na Biologia. Os conteúdos são locucionados pela jornalista, atriz e blogueira Ísis Nóbile Diniz, que também é especialista/pósgraduada em divulgação científica (XIS XIS, 2014) ${ }^{7}$.

Buscamos compreender intenções e significados, assumindo, então, uma postura hermenêutica, própria da pesquisa qualitativa (ALVES-MAZZOTTI, 1991; SILVERMANN, 2009). As etapas da análise qualitativa do corpus foram:

\footnotetext{
${ }^{7}$ Alguns dos vídeos do Além da Bio estão presentes no blog Xis Xis - pertencente à rede Science Blogs Brasil -, que também é gerenciado pela jornalista Ísis. Por ser ela a executora tanto dos vídeos quanto do blog, esse dado sobre sua formação acadêmica consta lá.
} 
1) "Pré-análise do vídeo", enfocando-se sua estrutura narrativa, conforme Quadro 3 (página 9);

2) Descrição das continuidades anafóricas do vídeo, mapeando-se a "referenciação sincrética", identificando, primeiramente, as propriedades semânticas do antecedente que são reiteradas por intermédio de alguma inscrição visual. Descrevemos as situações de correferencialidade e sequencialidade do ponto de vista semântico. De tal descrição, extraímos, por indução, três grandes unidades de significação, as quais constroem o objeto de discurso "bicho-preguiça" (antecipando, aqui, o caso do episódio que selecionamos para este artigo). Essas unidades são as facetas ou características principais que o bicho-preguiça incorpora no texto. As unidades de significação que constatamos relacionadas ao bicho-preguiça são: Lerdeza, Bicho-preguiça é objeto científico e Conhecimentos "de fora", memórias e personificação.

3) "Checagem" do semissimbolismo, isto é, da coerência entre os fatos narrativos (da etapa 1 ), de um lado, e os processos referenciais manifestados (imagens e lexemas que operam na continuidade e na progressão do episódio), de outro.

4) Análise dos procedimentos de referenciação, considerando os componentes da situação de midiatização da ciência.

Uma vez esclarecida a metodologia da pesquisa, passemos para a verificação dos resultados da análise.

\section{Análise e resultados}

Esta seção está organizada pelas seguintes etapas:

1) Informações gerais sobre o episódio audiovisual analisado;

2) Transcrição dos dados de fala do vídeo "Por que o bicho-preguiça é lerdo? ";

3) Dados preliminares sobre a gramática narrativa do vídeo - aqui sintetizados no Quadro 3, na página 9 -, que fornecem as categorias de conteúdo que "motivam" a situação de expressividade (parte visível) do vídeo;
4) Análise de alguns pontos da referenciação do vídeo, por meio da qual foi possível depreender o objeto de discurso bicho-preguiça, donde se sucedem variações.

O episódio "Por que o bicho-preguiça é lerdo?" foi postado no canal Além da Bio no dia 15 de maio de 2013. A apresentadora do vídeo, que produz sua fala dirigindo-se diretamente ao espectador, usuário do YouTube, mantém-se numa sala com parede branca ao fundo. Ao longo de sua fala, parecida com a de um tele-jornal, a jornalista utiliza diversos movimentos corporais, bem como são exibidos, na tela, algumas fotos e desenhos, que são materiais de edição que servem para complementar ou ajudar na explicação da jornalista. A descrição, no próprio ambiente de acesso ao vídeo, conta com as seguintes palavras, por escrito: "Neste episódio, a jornalista Isis Nóbile Diniz nos dá uma aula sobre o bicho-preguiça! Avalie o vídeo e deixe seu comentário! Ah, e inscreva-se no nosso canal! Muito obrigado" (ALÉM DA BIO, 2013b). Antecipamos, aqui, a informação de que o fim discursivo (o fim último) do vídeo, no nosso entender, é fazer crer que o bichopreguiça não é apenas aquele ser vagaroso como geralmente é concebido.

Subsequentemente, apresentamos a transcrição dos dados de fala do episódio. Os números à esquerda, na transcrição, são índices de cada segmento informacional. Na medida do possível, informamos, entre parênteses, na análise, o segmento informacional da transcrição em que determinada ocorrência a ser comentada se encontra.

Título, por escrito, da postagem do vídeo: Por que o bicho-preguiça é lerdo?

$\begin{array}{ll}1 & \text { ele é le:::rdo, devaga:::r } \\ 2 & \text { ele é tã:::o devagar, mas tã:::o devagar que } \\ 3 & \text { até recebeu no nome um adjetivo: } \\ 4 & \text { <bicho-preguiça> } \\ 5 & \text { na verdade o bicho-preguiça é le:::rdo porque } \\ 6 & \text { ele tem o metabolismo - } \downarrow \text { aquelas reações } \\ 7 & \text { quí::micas que acontecem dentro do nosso } \\ 8 & \text { corpo } \downarrow \text { - lento } \\ 9 & \text { mas >o bicho-preguiça é muito educadinho< } \\ 10 & \text { uma vez por semana ele desce lá da árvore } \\ \text { onde } & \\ 11 & \text { ele vive, onde ele se alimenta de folhas } \\ 12 & \text { jovens e brotos, <pra fazer cocô><na maior } \\ 13 & \text { desengonçadez e lerdeza do mu:::ndo> } \\ 14 & \text { apesar do bicho-preguiça ser lerdo, acredite } \\ 15 & \text { se quiser, ele é um excelente nadador }\end{array}$


e a gravidez dele é bem mais rápida que a nossa: dura de quatro a seis meses vamos respeitar as diferenças e ter muito carinho por esses animais que parecem (.) $>$ sorrir para as fotos<

tem gente que acha eles feios mas a felícia aqui acha eles mu:::ito bonitinhos

E se você gostou do nosso vídeo, deixe a preguiça de lado, dê um like aí no YouTube e nos ajude a divulgar o canal.

A gramática narrativa do vídeo (a lógica actancial, subjacente à textualização visível) fornece os conteúdos de base para que a referenciação, em seus múltiplos códigos, manifeste-se por aquelas formas, tais como se apresentam na progressão textual. No Quadro subsequente (Quadro 3), resumimos o percurso narrativo do episódio.

Quadro 3 - Organização semionarrativa do vídeo Por que o bicho-preguiça é lerdo?

\begin{tabular}{|c|c|}
\hline Enunciado & $\begin{array}{l}\text { Síntese da organização } \\
\text { semionarrativa do vídeo }\end{array}$ \\
\hline $\begin{array}{l}\text { Enunciado 1: } \\
\text { (segmentos } \\
1 \text { a } 4 \text { ) }\end{array}$ & $\begin{array}{l}\text { Situação de /não saber/ por que } \\
\text { o bicho-preguiça é lerdo; } \\
\text { Disforização (valoração } \\
\text { negativa) do bicho-preguiça; } \\
\text { Expansão do valor divertimento } \\
\text { (ligado à estratégia de captação } \\
\text { do discurso de DCM); } \\
\text { Ênfase no fazer (performance) } \\
\text { da jornalista: para o divertimento. }\end{array}$ \\
\hline $\begin{array}{l}\text { Enunciado } 2 \\
\text { (segmentos } \\
5 \text { a 8) }\end{array}$ & $\begin{array}{l}\text { Fortalecimento das modalidades } \\
\text { veridictórias (que constroem } \\
\text { verdades, mentiras, aparências, } \\
\text { etc.), por parte da jornalista, que } \\
\text { conferem existência ao actante } \\
\text { bicho-preguiça; } \\
\text { Modalidades veridictórias } \\
\text { sobredeterminadas pelo } \\
\text { destinador-manipulador voz da } \\
\text { ciência (o sujeito virtual que dota } \\
\text { Ísis de atributos para a ação); } \\
\text { Preenchimento de uma falta }{ }^{8} \text { : } \\
\text { programa narrativo de aquisição } \\
\text { do saber (por parte do actante } \\
\text { interlocutor). }\end{array}$ \\
\hline $\begin{array}{l}\text { Enunciado } 3 \\
\text { (segmentos } \\
9 \text { a 13) }\end{array}$ & $\begin{array}{l}\text { Continuidade da perspectiva } \\
\text { científica, } \\
\text { desenvolvida no Enunciado } 2 \text {. }\end{array}$ \\
\hline $\begin{array}{l}\text { Enunciado } 4 \\
\text { (segmentos } \\
14 \text { a 17) }\end{array}$ & $\begin{array}{l}\text { Ísis modaliza o estado do bicho- } \\
\text { preguiça; } \\
\text { O actante funcional bicho- } \\
\text { preguiça adquire } \\
\text { predicados modais. }\end{array}$ \\
\hline $\begin{array}{l}\text { Enunciado } 5 \\
\text { (segmentos } \\
18 \text { a 22) }\end{array}$ & $\begin{array}{l}\text { Nós (interlocutores + Ísis) em } \\
\text { movimento de conjunção (estar } \\
\text { com) com o respeito, em } \\
\text { proximidade com o "novo" bicho- } \\
\text { preguiça. Procura-se modalizar } \\
\text { não só o /saber/, mas também o } \\
\text { /ser/ do interlocutor. }\end{array}$ \\
\hline
\end{tabular}

Fonte: elaborado pelos autores.

Note-se que os segmentos informacionais 23 a 25, apesar de fazerem parte do vídeo, não são contemplados nas análises, porquanto suas proposições não apresentam referências ou menção ao bicho-preguiça.

Convém explicar o modo como a análise está estruturada: todas as ocorrências de construção do objeto "bicho-preguiça" estão subsumidas a determinada unidade de significação. As unidades serão explicitadas ao longo da seção. Ademais, cada enunciado - trecho retirado da elocução do vídeo -

\footnotetext{
8 Todo percurso narrativo pressupõe a sequência Falta $\rightarrow$ Busca $\rightarrow$ Exito/Fracasso, conforme a Semiótica.
} 
está numerado, em sequência, e exibe as ocorrências significativas para a análise em realce; cada enunciado (Enunciado 1, 2, 3 e assim por diante) antepõe-se aos comentários analíticos a ele atinentes.

Comecemos explorando os dados que edificam a unidade Lerdeza, atribuída ao bichopreguiça.

\section{Lerdeza}

\section{Enunciado 1: segmentos de 1 a 4}

ele é le:::rdo, devaga:::r

ele é tã:::o devagar, mas tã:::o devagar que

até recebeu no nome um adjetivo: <bicho-preguiça>

(ALÉM DA BIO, 2013b).

Primeiramente, durante a produção do Enunciado 1, simula-se o não saber na imagem que está à direita de Ísis na tela, como uma brincadeira de suspense. Em seguida, entretanto, ocorre a mudança na composição da imagem (Figura 1$)^{9}$, com 0 aparecimento da foto do bicho-preguiça, "revelandose" o tópico do enunciado verbal.

Figura 1 - Foto do bicho-preguiça na árvore

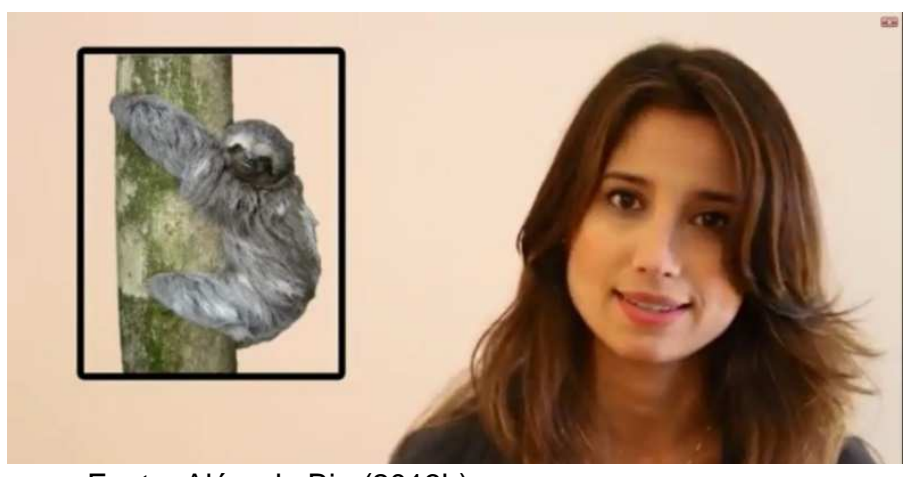

Fonte: Além da Bio (2013b).

Consideramos que a imagem gráfica (Figura 1) é uma anáfora correferencial cossignificativa, uma espécie de sinônimo do antecedente "bicho-preguiça" (do título). A imagem também está anaforicamente ligada ao "ele" (segmentos 1 e 2). A imagem é outra forma de significar algo já dito no cotexto. Constata-

\footnotetext{
9 A composição da imagem aqui mostrada, que tem a foto de um bicho-preguiça, é uma reconfiguração de uma figura antecedente, em que, em vez da foto, apresentavam-se os contornos do bicho-preguiça com seu interior preenchido na cor preta e de um ponto de interrogação na cor branca. Essa "primeira fase" da imagem pode ser consultada na Figura 2 (página 12), que mostra, então, o retângulo, com a forma "misteriosa" (revelada na Figura 1).
}

se, no entanto, que a fotografia não apenas faz progredir o texto, mas, também, i) acrescenta atributos ao objeto de discurso, com um retrato fiel do animal, satisfazendo ao fim demonstrativo, muito usual na midiatização da ciência, visto que serve como registro objetivo e ii) desempenha uma função ilustrativa e didática, conforme a restrição de legibilidade prevista pelo contrato de comunicação, na perspectiva de Charaudeau (2008).

Para edificar a unidade de significação Lerdeza, a repetição de lexemas que associam o animal à lerdeza é crucial: o uso do nome "bichopreguiça", enfatizando-se o adjetivo e a repetição dos adjetivos "lerdo" e "devagar".

O reiterável enquadre do "bicho-preguiça" como lerdo, que é insistente na fala de Ísis entre os segmentos 1 e 5 , pode ser vinculado aos gestos que ela utiliza justamente nesse período de sua elocução. As nomeações lexicais associadas à lerdeza são recategorizadas pelo gestuema pictográfico conforme nomenclatura de Rector e Trinta (2005) produzido por Ísis, averiguado na Figura 2.

Figura 2 - Gestuema pictográfico /lerdeza/ do Enunciado 1

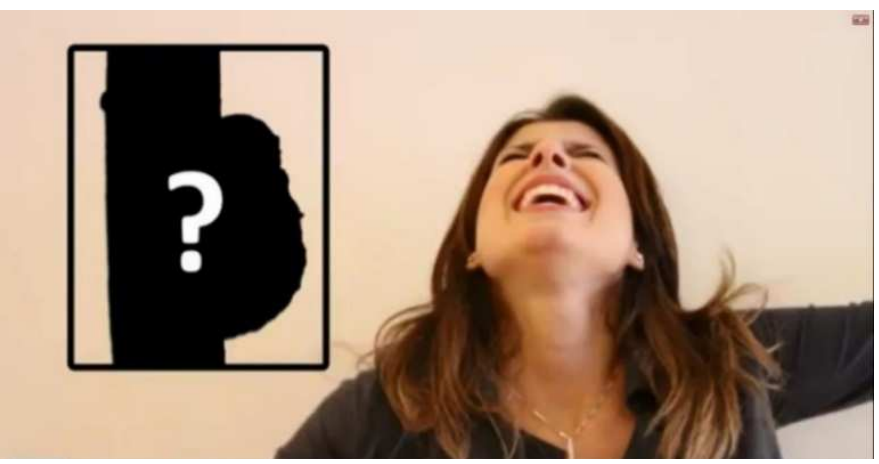

Fonte: Além da Bio (2013b).

A nosso ver, portanto, os gestuemas são anáforas correferenciais, fixando o traço semântica lerdeza.

O gestuema pictográfico (Figura 2) associado aos lexemas que salientam a lerdeza do bichopreguiça acabam por formalizar a disforização que esse animal recebe no plano de conteúdo adotando-se, aqui, o semissimbolismo. A propósito, o divertimento, como grandeza que se expande no nível 
narrativo durante o Enunciado 1, está muito ligada ao atributo de /não saber/ dos enunciatários - ou melhor, de conhecer apenas os estereótipos conferidos ao bicho-preguiça. Do ponto de vista discursivo, esta é uma estratégia do Além da Bio para cativar o espectador, pois a pronúncia dos lexemas associada à performance (gestuema) de Ísis orienta-se para a visada de captação, idiossincrática do contexto midiático.

Agora, passemos ao Enunciado 2, verificando a ocorrência que edifica a unidade Bicho-preguiça é objeto-científico.

\section{Bicho-preguiça é objeto científico}

O Enunciado 2 (segmentos 5 a 8) é o que impulsiona a duratividade, ou seja, o processo de consolidação da explicação científica, rompendo com a perspectiva anterior (do Enunciado 1), que é do divertimento - o divertimento é grandeza tensiva, que entra e sai da sequência videográfica, apesar do "contrato" ser entender a lerdeza do bicho-preguiça. Apresentamos o Enunciado 2 na sequência:

\section{Enunciado 2 - segmentos 5 a 8}

na verdade o bicho-preguiça é le:::rdo porque ele tem o metabolismo - $\downarrow$ aquelas reações quí::micas que acontecem dentro do nosso corpo $\downarrow$ - lento

(ALÉM DA BIO, 2013b).

Ísis esclarece que a lerdeza do bicho-preguiça provém do seu metabolismo lento. Essa perspectiva se deve à acentuação que o destinador-manipulador voz da ciência adquire nesse momento da narrativa, moldando o ato informativo de ísis (o que se materializa na modalização do /ser/ do animal, instanciado em enunciados estativos, de uma descrição). A construção do bicho-preguiça como objeto científico também acontece no Enunciado 3 (a seguir).

Enunciado 3 - segmentos 9 a 13 mas >o bicho-preguiça é muito educadinho< uma vez por semana ele desce lá da árvore onde ele vive, onde ele se alimenta de folhas jovens e brotos, <pra fazer cocô><na maior desengonçadez e lerdeza do mu::.ndo>

(ALÉM DA BIO, 2013b).

A triplicação do pronome "ele" nessa elocução, em tão pouco espaço, indica a economia de formalização coesiva, pois o foco é o conteúdo predicativo científico. Isso indicia que o animal é reconhecido como objeto da pesquisa biológica. $\mathrm{O}$ movimento de descrição do hábito do animal é reproduzido no desenho gráfico-digital (Figura 3).

Figura 3 - Desenho gráfico-digital /bicho-preguiça descendo a árvore para fazer cocô/

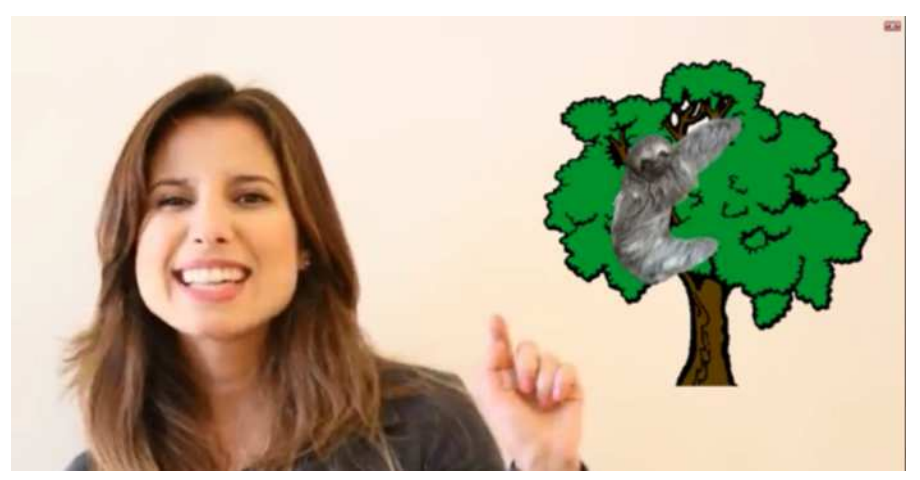

Fonte: Além da Bio (2013b).

A conotação de bicho-preguiça como ser que está no seu processo natural, objeto da curiosidade do observador ${ }^{10}$ também está alocada na imagem, de modo que ela é uma anáfora correferencial cossignificativa, pois "descreve" o que é dito no Enunciado 2.

Cumpre assinalar que esse enquadre do animal em seu habitat é fortemente motivado pelo plano de conteúdo dessa segunda etapa: pela modalização veridictória empreendida por Ísis, que determina a verdade do ser bicho-preguiça. Além do mais, vai se cumprindo o contrato do programa de

\footnotetext{
${ }^{10}$ Nossa interpretação dessa ocorrência é respaldada pelo fato de que, na elocução correspondente ao Enunciado 2, as modalidades veridictórias são postas em realce, na lógica actancial. Com isso, a fala da jornalista adquire uma perspectiva mais científica, devido à influência do destinador-manipulador ciência.
} 
aquisição do /saber/ - para preencher a falta -, examinando-se o semissimbolismo.

Examinemos, de agora em diante, os dados agrupados sob a unidade de significação Conhecimentos "de fora", memórias e personificação.

\section{Conhecimentos "de fora", memórias e personificação}

No Enunciado 2 constrói-se uma visão de cientificidade, conforme já visto antes, porém, agora, veremos os aspectos de personificação e ativação de conhecimentos prévios que ele enseja.

\section{Enunciado 2 - segmentos 5 a 8}

na verdade o bicho-preguiça é le::::rdo porque

ele tem o metabolismo - $\downarrow$ aquelas reações

quí::micas que acontecem dentro do nosso

corpo $\downarrow$ - lento

(ALÉM DA BIO, 2013b).

A imagem (Figura 4) que acompanha a fala da jornalista (a enunciação supracitada: Enunciado 2) está atrelada à perspectiva de acentuação da lerdeza do animal, característica dos primeiros enunciados do episódio.

Figura 4 - Desenho gráfico-digital /bicho-preguiça na rede/

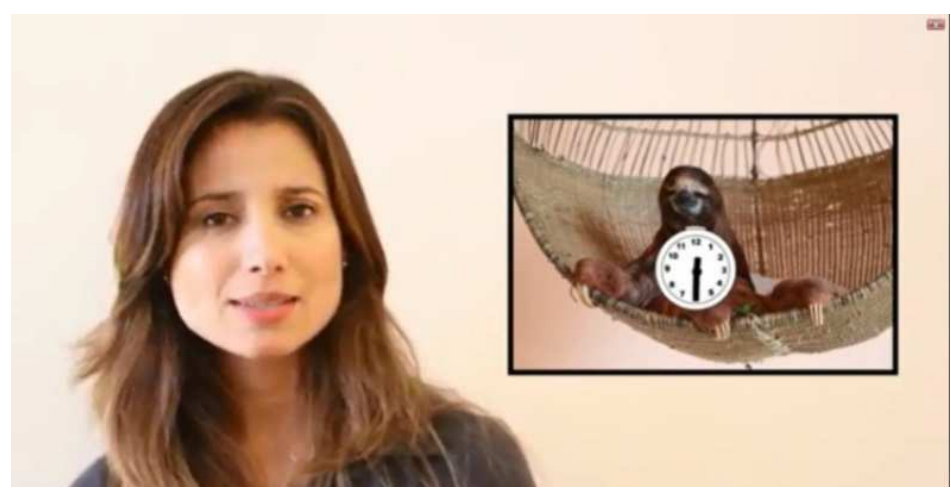

Fonte: Além da Bio (2013b).

A imagem, entretanto, acrescenta atributo de personificação, enriquecendo o valor circunstancial do bicho-preguiça, como lerdo ${ }^{11}$, pois o mostra prostrado na rede de balanço. É por causa disso que concebemos que esse desenho gráfico-digital é uma anáfora correferencial recategorizadora. A personificação recupera o conhecimento extratextual de que seres humanos se balançam na rede. Esse procedimento semiológico é uma forma de o Além da Bio aproximar-se do público-alvo, aproveitando os conhecimentos prévios desse público e apelando para o humor.

Personificação e conhecimentos extratextuais são também convocados nas ocorrências comentadas nos casos do Enunciado 5.

\section{Enunciado 5 - segmentos 14 a 17}

apesar do bicho-preguiça ser lerdo, acredite se quiser, ele é um excelente nadador e a gravidez dele é bem mais rápida que a nossa: dura de quatro a seis meses

(ALÉM DA BIO, 2013b).

$\mathrm{Na}$ trama semionarrativa do enunciado em questão, já se rompeu com a visão de bicho-preguiça como ser lerdo. O Enunciado 3, que enquadrou 0 bicho-preguiça como "muito educadinho", já anunciara essa nova modalização: o bicho-preguiça é modalizado em seu/ser/. Esse programa narrativo de Ísis, de valorização positiva do animal, recebe formalizações específicas nas anáforas, tanto linguísticas quanto visuais. Por exemplo, no Enunciado 5, o bicho-preguiça é designado como "excelente nadador" (segmento 15), o que é correferencial à imagem (Figura 5), editada estrategicamente - manipulada em sua dimensão eidética - com vistas ao humor.

\footnotetext{
${ }^{11}$ Afirmamos isto tendo como base o que acontece na estrutura semionarrativa (de imanência) do episódio, ou seja, na lógica actancial. Para edificar aquela figurativização da lerdeza, a busca dos actantes (para entrar em conjunção com o/saber/) é contraída para que outro valor circule no acontecimento do episódio: o valor do senso comum, das imitações, do pathos. A actante Ísis procede a imitações, reproduzindo o que já é dado sobre a noção de preguiça (por meio de sua fala e de sua performance, na manifestação), o que está condizente com a cenarização dos valores do interlocutor, em que aproveitam-se seus conhecimentos (e não aqueles da ciência, propriamente).
} 
Figura 5 - Desenho gráfico-digital /bichopreguiça nadador/

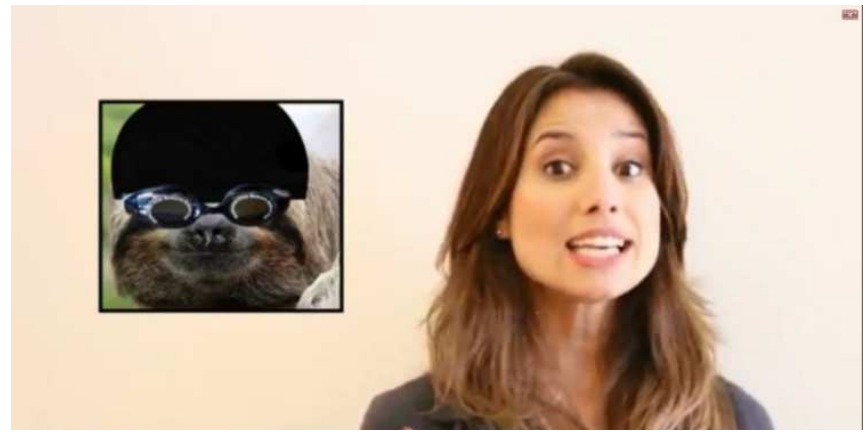

Fonte: Além da Bio (2013b).

O recurso de ativação dos conhecimentos sobre atividades humanas aparece, ainda, na ideia de que os bichos-preguiça sorriem, como mostra o Enunciado 6.

\section{Enunciado 6 - segmentos 18 a 22}

vamos respeitar as diferenças e ter muito carinho por esses animais que parecem (.) $>$ sorrir para as fotos $<$

(ALÉM DA BIO, 2013b)

A imagem (Figura 6) utilizada nesse momento da elocução reformula tal enquadre: o bicho-preguiça é registrado com rosto próximo à tela, para que seja possível detectar contornos de sua boca, um suposto "sorriso". Tal proximidade é uma manipulação da imagem em sua dimensão topológica (sob o olhar da Semiótica Plástica) para se gerar nova focalização do animal. E a anáfora visual (da manifestação) formaliza o processo narrativo (do plano de conteúdo) de conjunção dos actantes com o valor respeito - no caso, respeito com o bicho-preguiça. Ao modalizar-se - /ser/ do bicho-preguiça, intenta-se modalizar também o /saber/ e o /ser/ dos enunciatários, para que estes sejam levados a crer que o bicho-preguiça é muito mais do que apenas um animal lerdo.
Figura 6 - Desenho gráfico-digital /bicho-preguiça sorrindo/

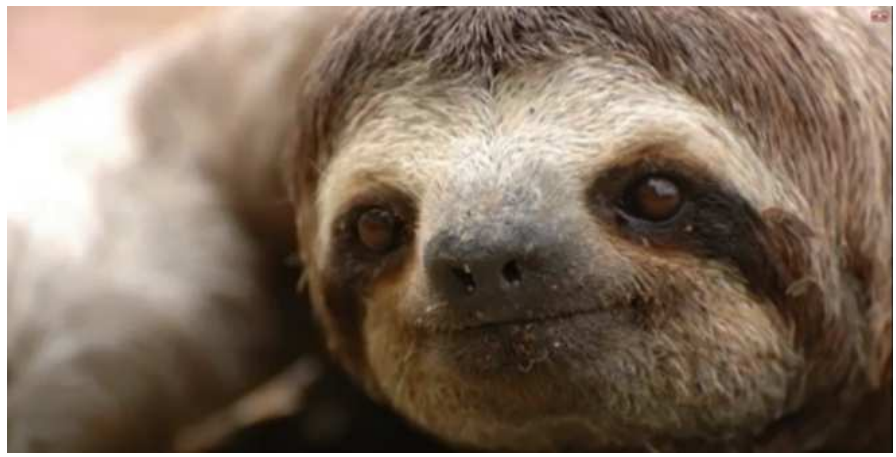

Fonte: Além da Bio (2013b).

Consideramos as três unidades de significação constatadas dão conta de se observar a referenciação sincrética do episódio, a qual é sustentada pelo semissimbolismo. As modalidades veridictórias que são evidenciadas na unidade "Bichopreguiça é objeto científico" coadunam-se à finalidade mais informativa da DCM, que mobiliza a restrição de seriedade desse contrato comunicativo e resulta em escolhas linguísticas e semiológicas que fazem durar o efeito de cientificidade. Mas há momentos em que o fazer-sentir (outra visada, própria da DCM) interfere na produção, modulando o /ser/ do bicho-preguiça, pelo humor, pela personificação, etc.

\section{Conclusões e considerações finais}

Constatamos que, no vídeo examinado, o projeto de dizer é sobrepor a uma visão pejorativa do bicho-preguiça uma nova visão, a de que o animal possui diversas qualidades, como ser educado e contar com uma gestação rápida. Os sintagmas anafóricos e também as imagens (sobretudo a Figura 5) que funcionam, a nosso ver, como anáforas, contribuem para edificar tal representação, orientada para o fim discursivo de fazer crer.

Até o segmento 14 - em que há a última ocorrência do nome "bicho-preguiça" -, enfatiza-se a lerdeza como atributo negativo: o bicho-preguiça é disforizado. Do segmento 15 em diante, essa conotação praticamente desaparece. Elementos que realçam a lerdeza (como o adjetivo "devagar" e os gestuemas pictográficos) são, então, cabíveis no 
cotexto que se orienta para aproximar-se do espectador, o que é motivado pela engenharia lógica da narratividade do texto: o divertimento. Já a partir do segmento 15, o bicho-preguiça obtém atributos positivos, sendo euforizado.

O fim discursivo do vídeo é convencer o espectador sobre as boas qualidades do bichopreguiça, para além do informar e do explicar, visadas também detectáveis dentro do texto - sobretudo quando se produz o efeito de cientificidade (Enunciados 2 e 3). Para tanto, convocou-se, manifestamente, expressões visuais que fossem elucidativas (a foto do bicho-preguiça como que subindo na árvore, por exemplo), o que revela que a progressão textual se apoia também na imagem, no nosso corpus.

Há ocorrências que ativam conteúdos armazenados na memória dos parceiros da atividade linguageira, como a figurativização do bicho-preguiça na rede de balanço. Para que efetivamente sejam acessados os enquadres dos objetos é preciso recorrer à bagagem mental: experiências com natação, com tiragem de foto, etc.

Nossa análise também demonstrou que 0 aparato visual pode atender a propósitos variados: informar, veicular uma metáfora (como no caso do bicho-preguiça "nadador", porque o traço de atleta é figurado), descontrair, ativar conhecimentos de mundo, etc., sendo estrategicamente elaborados para provocar reações no espectador. Ressalta-se que essas diversas "anáforas visuais" são importantes estratégias de dramatização realista, de construção objetiva do mundo, seguindo as ideias de Charaudeau (2009).

O alcance explanatório da análise provém da checagem do semissimbolismo do texto. Mas as marcas de referenciação são influenciadas, também, sobremaneira, por fatores discursivos, notadamente pelas restrições do contrato de midiatização da ciência, como procurou-se mostrar ao longo da análise.

Nossa proposta de análise merece, ainda, discussão e refinamentos. Mas acreditamos que esta pesquisa contribui para uma revisão nas noções de textualidade, referenciação e anáfora. Ademais, contemplamos, aqui, criações discursivas capazes de beneficiar as atividades de DC ou de jornalismo científico.

A crescente hibridização dos meios, que desafiam as práticas de leitura e produção textual, oportuniza que demos atenção a esses novos artefatos que potencializam os letramentos múltiplos que perpassam C\&T. Então, futuras pesquisas ainda poderão incrementar essa agenda de pesquisa que se volta para as múltiplas semioses da divulgação científica, examinando outros valores, qualidades e representações que se atrelam aos objetos vistos sob a ótica da ciência (ou de suas "testemunhas midiáticas".

\section{Referências}

ALÉM DA BIOa. Sobre. [S.I.], 19/03/2013. Disponível em: <https://www.youtube.com/channel/UCEaqD42z J2ONPcxafA6gT4A/about>. Acesso em: $28 \mathrm{fev}$. 2016.

ALÉM DA BIOb. Por que o bicho-preguiça é lerdo? [S.I.]: Canal Além da Bio, 15 mai. 2013. Duração $1 \min 34$ s. Disponível em: $<$ https://www.youtube.com/watch?v=tyJxxhp4Ac Q>. Acesso em: 6 jul. 2014.

ALVES-MAZZOTTI, Alda Judith. O planejamento de pesquisas qualitativas em Educação. Cadernos de Pesquisa (Fundação Carlos Chagas. Impresso), São Paulo, n. 77, p. 53-61, mai. 1991.

BARROS, Diana Luz Pessoa de. Teoria semiótica do texto. São Paulo: Ática, 1990. 96 p.

Teoria do Discurso. Fundamentos semióticos. 3. ed. São Paulo: Humanitas, 2001. $172 \mathrm{p}$.

CAVALCANTE, Mônica Magalhães. Expressões referenciais - uma proposta classificatória. Cadernos de Estudos Linguísticos, Campinas, v. 44, n. 1, p. 105-118, jan./jun. 2003.

Referenciação: sobre coisas ditas e não ditas. Fortaleza: Edições UFC, 2011. 192 p.

CHARAUDEAU, Patrick; MAINGUENEAU, Dominique. Dicionário de análise do discurso. 2 ed. São Paulo: Contexto, 2004. 555 p. 
CHARAUDEAU, Patrick. La médiatisation de la science: clonage, OGM, manipulations génétiques. 1. ed. Bruxelas: De Boeck, 2008. $128 \mathrm{p}$.

Linguagem e discurso: modos de organização. 1 ed. São Paulo, Contexto, 2009, $256 \mathrm{p}$.

Discurso das mídias. São Paulo: Contexto, 2006. 285 p.

CUSTÓDIO FILHO, V. Múltiplos fatores, distintas interações: esmiuçando o caráter heterogêneo da referenciação. 2011. 329 p. Tese (Doutorado em Linguística) - Programa de Pós-Graduação em Linguística, Universidade Federal do Ceará (UFC), Fortaleza, 2011.

DUBOIS, Philippe. Cinema, vídeo, Godard. 2. ed. São Paulo: Cosac Naify, 2004. 323 p.

EXAME/ AFP, de INFO Online. Canais do YouTube popularizam ciência com linguagem simples e humor. São Paulo, 18/09/2015. Disponível em: <http://exame.abril.com.br/tecnologia/noticias/cana is-no-youtube-popularizam-ciencia-com-

linguagem-simples-e-humor>. Acesso em: 13 nov. 2015.

FIORIN, José Luiz. Elementos de análise do discurso. 15. ed. São Paulo: Contexto/EDUSP, 2014. 126 p.
GREIMAS, Algirdas Julien; COURTÉS, Joseph. Dicionário de semiótica. $2^{a}$ ed. São Paulo: Contexto, 2013. 538 p.

GIERING, Maria Eduarda. Referenciação e hiperestrutura em textos de divulgação científica para crianças. Linguagem em (Dis)curso (Impresso), Tubarão, v. 12, n. 3, p. 683-710, set./dez. 2012.

Semiolinguística, enunciação e contexto de comunicação: o caso da notícia de divulgação científica dirigida a crianças. Cadernos de Pesquisas em Linguística (PUCRS), Porto Alegre, v. 5, n. 1, p. 126-137, nov. 2010.

PIETROFORTE, Antonio Vicente Seraphim. Análise do texto visual: a construção da imagem. 1. ed. São Paulo: Contexto, 2008. 112 p.

RECTOR, Mônica; TRINTA, Aluizio Ramos. Comunicação do corpo. 4 ed. São Paulo: Ática, 2005. 88 p.

SILVERMAN, David. Interpretação de dados qualitativos: métodos para análise de entrevistas, textos e interações. 3. ed. Porto Alegre: Artmed, 2009. 376 p.

SCIENCE BLOGS BRASIL. Sobre. Suzano - SP, 2013. Disponível em: <http://scienceblogs.com.br/sobre/>. Acesso em: 17 set. 2015.

XIS XIS. Blog XIS XIS. Suzano - SP, [S.I.]. Disponível em:<http://scienceblogs.com.br/xisxis/>. Acesso em: 3 jul. 2014

\section{COMO CITAR ESSE ARTIGO}

ZANDONAI, Marcos Filipe; GIERING, Maria Eduarda. Referenciação e sincretismo: o caso dos vídeos que divulgam ciência no Youtube. Signo, Santa Cruz do Sul, v. 41, n. 71, set. 2016. ISSN 1982-2014. Disponível em: <https://online.unisc.br/seer/index.php/signo/article/view/7242>. Acesso em: http://dx.doi.org/10.17058/signo.v41i71.7242. 